\title{
Health system costs for cancer medications and radiation treatment in Ontario for the 4 most common cancers: a retrospective cohort study
}

\author{
Nicole Mittmann MSc PhD, Ning Liu MSc PhD, Stephanie Y. Cheng MSc, Soo Jin Seung HBSc, \\ Farah E. Saxena MPH, Nicole J. Look Hong MD MSc, Craig C. Earle MD MSc, \\ Matthew C. Cheung MD SM, Natasha B. Leighl MD MMSc, Natalie G. Coburn MD MPH, \\ Carlo DeAngelis PharmD, William K. Evans MD
}

Abstract

Background: Previous costing and resource estimates for cancer have not been complete owing to lack of comprehensive data on cancerrelated medication and radiation treatment. Our objective was to calculate the mean overall costs per patient of cancer-related medications and radiation, as well as by disease subtype and stage, in the first year after diagnosis for the 4 most prevalent cancers in Ontario.

Methods: We conducted a retrospective cohort study using provincial health administrative databases to identify population health system resources and costs for all patients diagnosed with breast, colorectal, lung or prostate cancer between Jan. 1, 2010, and Dec. 31, 2015 in Ontario. The primary outcome measure was the overall average cost per patient in the 365 days after diagnosis for cancer-related medications and radiation treatment, calculated with the use of 2 novel costing algorithms. We determined the cost by disease, disease subtype and stage as secondary outcomes.

Results: There were 168316 Ontarians diagnosed with cancer during the study period, 50141 with breast cancer, 38108 with colorectal cancer, 34809 with lung cancer and 45258 with prostate cancer. The mean per-patient cost for cancer-related medications was $\$ 8167$ (95\% confidence interval [Cl] \$8023-\$8311), \$6568 (95\% Cl \$6446-\$6691), \$2900 (95\% Cl \$2816-\$2984) and \$1211 (95\% Cl \$1175-\$1247) for breast, colorectal, lung and prostate cancer, respectively. The corresponding mean radiation treatment costs were $\$ 18529$ (95\% Cl $\$ 18415-$ \$18 643), \$15 177 (95\% Cl \$14 899-\$15 456), \$10 818 (95\% Cl \$10 669-\$10 966) and \$16 887 (95\% Cl \$16 648-\$17 125). In general, stage III and IV cancers were the most expensive stages for both medications and radiation across all 4 disease sites.

Interpretation: Our work updates previous costing estimates to help understand costs and resources critical to health care system planning in a single-payer system. More refined costing estimates are useful as inputs to allow for more robust health economic modelling and health care system planning.

I $\mathrm{n}$ an age of shrinking health care dollars and expensive treatments, there is a need to understand the resources and costs associated with treatments. Decision-makers need this type of data when conducting health technology assessments, budget impact analyses and economic analyses.

Cancer is burdensome clinically to patients. It is becoming increasingly burdensome economically and is associated with substantial financial toxicity (problems a patient has related to the cost of treatment). ${ }^{1}$ When planning system health services, it is important to understand both the resources and costs associated with cancer treatment. In most cases, it is not possible to capture direct costs with a population-level approach.

In this study, we used previously constructed costing algorithms to examine cancer-related medication and radiation resources and costing across the 4 most common cancers breast, colorectal, lung and prostate - in Ontario. The overarching objective was to examine the costs for cancer-related medications and radiation treatment in the first year after diagnosis. Secondary objectives were to compare the costs for cancer-related medications and radiation treatment between patients with different stages of cancer at the time of diagnosis, within the same type of cancer and by cancer subtype, and between patients diagnosed with different types of cancer, across different stages and by cancer subtype.

Competing interests: Natalie Coburn receives salary support from Cancer Care Ontario and the Sherif and MaryLou Hanna Chair in Surgical Oncology at the Sunnybrook Research Institute. No other competing interests were declared.

This article has been peer reviewed.

Correspondence to: Nicole Mittmann, nicole.mittmann@sunnybrook.ca CMAJ Open 2020. DOI:10.9778/cmajo.20190114 


\section{Methods}

\section{Study setting and design}

The study was set in Ontario. We used a retrospective cohort study design to identify population-level health system resources and costs for patients diagnosed with incident female breast (International Classification of Diseases for Oncology, Third Revision [ICD-O-3] codes C500-C509), lung (ICD-O-3 C340-C343, C348-C349), colorectal (ICD-O-3 C18.X [excluding C181 (appendix)], C199, C209) or prostate (ICDO-3 C61) cancer from Jan. 1, 2010, to Dec. 31, 2015.

\section{Data sources}

Clinical and health administrative databases including the Activity Level Reporting database, New Drug Funding Program, Ontario Drug Benefit, National Ambulatory Care Reporting System, Ontario Health Insurance Plan and Management Information System were linked by means of unique encoded identifiers and analyzed at ICES. ICES is an independent, nonprofit research institute whose legal status (Prescribed Entity) under the Ontario Personal Health Information and Protection of Privacy Act allows it to collect and analyze health care and demographic data, without consent, for health system evaluation and improvement. These administrative databases allow researchers to identify and quantify health system resources, after which they can be valued with unit costs.

ICES encodes a personal identifier, which allows linkage of data from different care providers and across sectors in health administrative databases. People without valid health insurance or ineligible for health insurance were excluded from the analysis.

We used the index cancer if a patient was diagnosed with more than 1 of the 4 cancer types during the accrual period. Demographic variables included those available from the administrative databases, including age, gender, location of residence (urban [population $\geq 10000$ ] v. rural [population $<10000^{2}$ ), comorbidity, income (defined by neighbourhood income quintile ${ }^{2}$ ) and exposure to health system resources. The end of follow-up was defined as the earliest of the date of death, 1 year after diagnosis of the index cancer or 1 day before diagnosis of a second primary cancer. Costs were adjusted for 365 days and were not prorated if follow-up duration was less than 365 days.

\section{Costing algorithm}

Wodchis and colleagues ${ }^{3}$ developed a costing algorithm based on the Ontario health administrative databases that allows the calculation of person-level health care costs (referred hereinafter as the person-level case-costing methodology). In this algorithm, the cost of services that are episodic in nature is estimated by means of a cost-per-weighted-case methodology, whereas the cost of services that are reported by visits or claims can be obtained more directly. Several investigators have used the person-level case-costing methodology to estimate the costs of different diseases across the continuum of care. ${ }^{4-8}$

To enhance the person-level case-costing methodology with comprehensive costing for cancer treatments, we recently created 2 additional oncology-specific costing algorithms using Ontario health administrative databases, 1 for cancer-related medications (costing algorithm for cancer medication) and 1 for radiation treatment (costing algorithm cancer for radiation). ${ }^{9}$ The algorithms enable more specific, comprehensive cancer costing evaluations in which costs are aggregated across physicians and other allied health care professionals as well as institutions by modality of treatment. The algorithms and their validation are described elsewhere. ${ }^{9}$

\section{Outcomes}

We applied the costing algorithm for cancer medication and the costing algorithm for cancer radiation to the 4 cancer cohorts to identify direct health system (total and disaggregated) undiscounted costs based on a single-payer government perspective (Ontario). We used a micro-economic (bottom-up) approach to determine the cost of treatment at the level of the individual patient encounter. When health sector costs at the individual patient level were not available (e.g., system or institutional costs), we used a macro-economic (top-down) approach to allocate aggregated costs to each patient encounter.

We calculated direct treatment costs from the perspective of the Ontario public health care payer; costs incurred by the individual patient or private insurers were not addressed. The costing algorithm for cancer medication estimated the perperson costs for patients who received cancer-related medications, both treatment and supportive. The costing algorithm for cancer radiation estimated the per-person costs for patients undergoing radiation therapy. Costs were disaggregated into planning, treatment and operational (e.g., physicist time, unit funding) costs. We determined standard costs (mean and standard deviation [SD]) for all patients in the cohort who used the resource (when evaluable clinically). Real-time costs were used, and, thus, discounting was not used in the analysis.

\section{Statistical analysis}

The primary analysis calculated the mean overall cost per patient for cancer-related medication and for radiation, for each disease (breast, colorectal, lung and prostate cancer) and disease stage (I-IV). A secondary analysis examined cost by disease subtype. For breast cancer, subtypes included hormone receptor (estrogen or progesterone or both) positive + HER2 overexpressed; hormone receptor positive + HER2 negative; hormone receptor negative + HER2 overexpressed; and hormone receptor negative + HER2 negative. For lung cancer, we organized costs into non-small cell and small cell. Colorectal cancer was organized into colon and rectal. We calculated the cost by stage for prostate cancer. We also calculated costs for patients who survived for 2 or more years to avoid any overlap or inclusion of end-of-life or palliative care costs.

\section{Ethics approval}

The use of data in this project was authorized under section 45 of Ontario's Personal Health Information Protection Act, which does not require review by a research ethics board. 


\section{Results}

There were 168316 Ontarians diagnosed with breast, colorectal, lung or prostate cancer between Jan. 1, 2010, and Dec. 31, 2015 (Table 1). The mean age of all patients at diagnosis was 66.1 (SD 12.4) years; it was highest for those with lung cancer (68.8 [SD 10.4] yr) and lowest for those with breast cancer (61.3 yr [SD $13.7 \mathrm{yr}])$. The gender distribution was similar for colorectal and lung cancer. The overall mean follow-up duration was 10.4 (SD 3.5) months.

\section{Breast cancer}

A total of 50141 women were diagnosed with breast cancer, most at an early stage (stages I-II). Of the 50 141, 46574

\begin{tabular}{|c|c|c|c|c|c|}
\hline \multirow[b]{2}{*}{ Characteristic } & \multicolumn{5}{|c|}{ No. (\%) of patients ${ }^{*}$} \\
\hline & $\begin{array}{c}\text { Breast cancer } \\
n=50141\end{array}$ & $\begin{array}{c}\text { Colorectal cancer } \\
n=38108\end{array}$ & $\begin{array}{l}\text { Lung cancer } \\
n=34809\end{array}$ & $\begin{array}{c}\text { Prostate cancer } \\
n=45258\end{array}$ & $\begin{array}{c}\text { Total } \\
n=168316\end{array}$ \\
\hline Female & $50141(100.0)$ & $17327(45.5)$ & $17001(48.8)$ & $0(0.0)$ & $84469(50.2)$ \\
\hline \multicolumn{6}{|l|}{ Age at cancer diagnosis, yr } \\
\hline Mean \pm SD & $61.3 \pm 13.7$ & $68.4 \pm 13.3$ & $68.8 \pm 10.4$ & $67.5 \pm 9.5$ & $66.1 \pm 12.4$ \\
\hline Median (IQR) & $61(51-71)$ & $69(59-79)$ & $69(62-76)$ & $67(61-74)$ & $66(58-75)$ \\
\hline Rural residence $\dagger$ & $6176(12.3)$ & $5642(14.8)$ & $5523(15.9)$ & $6513(14.4)$ & 23854 (14.2) \\
\hline \multicolumn{6}{|l|}{ Neighbourhood income quintile ${ }^{2}$} \\
\hline Lowest & 8497 (16.9) & 7217 (18.9) & $8232(23.6)$ & $6934(15.3)$ & 30880 (18.3) \\
\hline Second lowest & $9608(19.2)$ & 7754 (20.3) & $7538(21.7)$ & $8442(18.7)$ & $33342(19.8)$ \\
\hline Middle & $9918(19.8)$ & 7705 (20.2) & $6772(19.5)$ & $8910(19.7)$ & 33305 (19.8) \\
\hline Second highest & $10873(21.7)$ & 7804 (20.5) & $6479(18.6)$ & $9804(21.7)$ & $34960(20.8)$ \\
\hline Highest & $11048(22.0)$ & $7461(19.6)$ & 5635 (16.2) & $10986(24.3)$ & $35130(20.9)$ \\
\hline Missing & $197(0.4)$ & $167(0.4)$ & $153(0.4)$ & $182(0.4)$ & $699(0.4)$ \\
\hline \multicolumn{6}{|l|}{ Cancer stage at diagnosis } \\
\hline $\mathrm{I}$ & $20759(41.4)$ & $8269(21.7)$ & $6104(17.5)$ & $10154(22.4)$ & $45286(26.9)$ \\
\hline II & $18607(37.1)$ & $9124(23.9)$ & $2855(8.2)$ & $22103(48.8)$ & 52689 (31.3) \\
\hline III & $6786(13.5)$ & $10755(28.2)$ & $6989(20.1)$ & $5664(12.5)$ & 30194 (17.9) \\
\hline IV & $2433(4.9)$ & $6848(18.0)$ & $17714(50.9)$ & $4058(9.0)$ & $31053(18.4)$ \\
\hline Unknown & $1556(3.1)$ & $3112(8.2)$ & $1147(3.3)$ & $3279(7.2)$ & $9094(5.4)$ \\
\hline \multicolumn{6}{|l|}{$\begin{array}{l}\text { Charlson Comorbidity Index } \\
\text { score }\end{array}$} \\
\hline 0 & $13232(26.4)$ & $20017(52.5)$ & 13051 (37.5) & $17244(38.1)$ & $63544(37.8)$ \\
\hline 1 & $1896(3.8)$ & $4017(10.5)$ & $3543(10.2)$ & $2529(5.6)$ & $11985(7.1)$ \\
\hline$\geq 2$ & $1215(2.4)$ & $2723(7.1)$ & $3123(9.0)$ & $1832(4.0)$ & $8893(5.3)$ \\
\hline Not admitted to hospital & $33798(67.4)$ & $11351(29.8)$ & $15092(43.4)$ & $23653(52.3)$ & $83894(49.8)$ \\
\hline \multicolumn{6}{|l|}{ Months of follow-up§ } \\
\hline Mean \pm SD & $11.4 \pm 2.3$ & $10.1 \pm 3.9$ & $7.7 \pm 4.6$ & $11.6 \pm 1.8$ & $10.4 \pm 3.5$ \\
\hline Median (IQR) & $12(12-12)$ & $12(12-12)$ & $9(3-12)$ & $12(12-12)$ & $12(12-12)$ \\
\hline Died during follow-up§ & $1782(3.6)$ & $6369(16.7)$ & $17745(51.0)$ & $1535(3.4)$ & 27431 (16.3) \\
\hline Died within 2 yr after diagnosis & $3557(7.1)$ & $9971(26.2)$ & 23506 (67.5) & $3256(7.2)$ & $40290(23.9)$ \\
\hline Had an entire year of follow-up§ & 46574 (92.9) & $29434(77.2)$ & $15482(44.5)$ & $42865(94.7)$ & $134355(79.8)$ \\
\hline \multicolumn{6}{|l|}{ Reason for end of follow-up§ } \\
\hline Died during follow-up & $1782(3.6)$ & $6369(16.7)$ & $17745(51.0)$ & $1535(3.4)$ & $27431(16.3)$ \\
\hline Had second cancer & $1787(3.6)$ & $2314(6.1)$ & $1598(4.6)$ & $865(1.9)$ & $6564(3.9)$ \\
\hline End of 1-yr follow-up & 46572 (92.9) & $29425(77.2)$ & $15466(44.4)$ & $42858(94.7)$ & $134321(79.8)$ \\
\hline $\begin{array}{l}\text { Note: } \mathrm{Cl}=\text { confidence interval, } \mathrm{IQR}= \\
{ }^{*} \text { Except where noted otherwise. } \\
\text { tUrban = population } 10000 \text { or more, } \\
\text { tCalculated with the use of hospital a } \\
\text { \$End of follow-up was defined as the }\end{array}$ & $\begin{array}{l}\text { nge, } S D=\text { st } \\
\text { ion less than } \\
\text { in the } 2 \text { year } \\
\text { of death, } 1 \text {. }\end{array}$ & ation. & . & r. & \\
\hline
\end{tabular}


(92.9\%) had an entire year of follow-up, and 33798 (67.4\%) were not admitted to hospital (Table 1). The majority of women used cancer-related medications (38 484 [76.8\%]; mean cost $\$ 8167,95 \%$ CI \$8023-\$8311) and radiation services (40 659 [81.1\%]; mean cost $\$ 18529$, 95\% CI $\$ 18415$ $\$ 18$ 643) within 1 year after diagnosis (Table 2, Table 3). Overall cancer-related drug costs and radiation costs increased by stage (Figure 1A, Figure 2A). Compared to women who were HER2-, women who were HER2 + had 6- to 10-fold higher overall cancer-related drug costs (Appendix 1, Supplemental Table S1, available at www. cmajopen.ca/content/8/1/E191/suppl/DC1). Radiation costs were highest for stage III breast cancer.

\section{Colorectal cancer}

A total of 38108 patients had a diagnosis of colorectal cancer; there were slightly more men than women $(20781$ [54.5\%] v. 17327 [45.5\%]). Of those staged, just under half (17 603 [46.2\%]) were diagnosed at stage III-IV (Table 1). A total of 6369 patients (16.7\%) died in the year following their diagnosis.

The stage IV group had the highest mean overall costs for cancer-related medications (\$11 442, 95\% CI \$11 075$\$ 11809$ ), and the stage III group had the highest mean overall costs for radiation treatment (\$18 853, 95\% CI \$18 439$\$ 19$ 266) (Tables 2 and 3). The cost of cancer-related treatment medications was highest among patients with stage IV disease (Figure 1B). Overall costs for medications were similar for colon and rectal disease, but radiation costs, especially for treatment, were higher in the rectal disease group (Appendix 1, Supplemental Tables S1 and S2).

\section{Lung cancer}

There were 34809 lung cancer cases, half of which (17 714 [50.9\%]) were diagnosed at stage IV. There was an equal split in cancer frequency between the genders. Just over half of patients (17 745 [51.0\%]) died within 1 year of diagnosis, and more than two-thirds (23 506 [67.5\%]) died within 2 years of diagnosis (Table 1). A total of 27673 patients $(79.5 \%)$ used cancer-related medications, and $23158(66.5 \%)$ received radiation treatment.

The mean overall cost for cancer-related drugs was $\$ 2900$ (95\% CI \$2816-\$2984) and increased by stage of disease. The mean overall cost for radiation treatment was \$10 818 (95\% CI \$10 669-\$10 966), with highest costs for stages II and III disease (Tables 2 and 3). Treatment drugs were more costly than supportive drugs (Figure 1C), and radiation treatment was more costly than planning and operational costs (Figure 2C). When organized into non-small cell and small cell lung cancer cases, costs of cancer-related medication were highest in stage IV for non-small cell cancer and in stage II for small cell cancer (Appendix 1, Supplemental Table S1). For radiation, stage IV cancers had the highest costs.

\begin{tabular}{|c|c|c|c|c|c|c|}
\hline Cancer type/measure & Overall & Stage I & Stage II & Stage III & Stage IV & Stage unknown \\
\hline \multicolumn{7}{|l|}{ Breast } \\
\hline No. of patients & 50141 & 20759 & 18607 & 6786 & 2433 & 1556 \\
\hline No. (\%) used medication & $38484(76.8)$ & $13111(63.2)$ & 16061 (86.3) & $6451(95.1)$ & 2009 (82.6) & $852(54.8)$ \\
\hline Cost, $\$$, mean $(95 \% \mathrm{Cl})^{*}$ & $\begin{array}{c}8167 \\
(8023-8311)\end{array}$ & $\begin{array}{c}5409 \\
(5207-5611)\end{array}$ & $\begin{array}{c}8519 \\
(8314-8724)\end{array}$ & $\begin{array}{c}12046 \\
(11657-12 \text { 434) }\end{array}$ & $\begin{array}{c}12460 \\
(11328-13592)\end{array}$ & $\begin{array}{c}4454 \\
(3656-5252)\end{array}$ \\
\hline \multicolumn{7}{|l|}{ Colorectal } \\
\hline No. of patients & 38108 & 8269 & 9124 & 10755 & 6848 & 3112 \\
\hline No. (\%) used medication & 27749 (72.8) & $4675(56.5)$ & $6421(70.4)$ & $9482(88.2)$ & $5634(82.3)$ & $1537(49.4)$ \\
\hline Cost, \$, mean $(95 \% \mathrm{Cl})^{*}$ & $\begin{array}{c}6568 \\
(6446-6691)\end{array}$ & $\begin{array}{c}785 \\
(683-887)\end{array}$ & $\begin{array}{c}2778 \\
(2624-2933)\end{array}$ & $\begin{array}{c}9637 \\
(9431-9843)\end{array}$ & $\begin{array}{c}11442 \\
(11 \text { 075-11 809) }\end{array}$ & $\begin{array}{c}3196 \\
(2782-3610)\end{array}$ \\
\hline \multicolumn{7}{|l|}{ Lung } \\
\hline No. of patients & 34809 & 6104 & 2855 & 6989 & 17714 & 1147 \\
\hline No. (\%) used medication & $27673(79.5)$ & $4470(73.2)$ & $2469(86.5)$ & $6050(86.6)$ & $13910(78.5)$ & $774(67.5)$ \\
\hline Cost, $\$$, mean $(95 \% \mathrm{Cl})^{*}$ & $\begin{array}{c}2900 \\
(2816-2984)\end{array}$ & $\begin{array}{c}612 \\
(546-679)\end{array}$ & $\begin{array}{c}1415 \\
(1278-1552)\end{array}$ & $\begin{array}{c}2291 \\
(2155-2428)\end{array}$ & $\begin{array}{c}4207 \\
(4060-4354)\end{array}$ & $\begin{array}{c}2129 \\
(1673-2585)\end{array}$ \\
\hline \multicolumn{7}{|l|}{ Prostate } \\
\hline No. of patients & 45258 & 10154 & 22103 & 5664 & 4058 & 3279 \\
\hline No. (\%) used medication & 22599 (49.9) & 3231 (31.8) & $11763(53.2)$ & $2798(49.4)$ & $3276(80.7)$ & $1531(46.7)$ \\
\hline Cost, $\$$, mean $(95 \% \mathrm{Cl})^{*}$ & $\begin{array}{c}1211 \\
(1175-1247)\end{array}$ & $\begin{array}{c}268 \\
(239-296)\end{array}$ & $\begin{array}{c}966 \\
(932-1000)\end{array}$ & $\begin{array}{c}825 \\
(763-888)\end{array}$ & $\begin{array}{c}3236 \\
(3060-3413)\end{array}$ & $\begin{array}{c}1461 \\
(1303-1620)\end{array}$ \\
\hline
\end{tabular}




\begin{tabular}{|c|c|c|c|c|c|c|}
\hline Cancer type/measure & Overall & Stage I & Stage II & Stage III & Stage IV & Stage unknown \\
\hline \multicolumn{7}{|l|}{ Breast } \\
\hline No. of patients & 50141 & 20759 & 18607 & 6786 & 2433 & 1556 \\
\hline No. (\%) used radiation & 40659 (81.1) & 17206 (82.9) & $15306(82.3)$ & $6054(89.2)$ & $1487(61.1)$ & $606(38.9)$ \\
\hline Cost, \$, mean $(95 \% \mathrm{Cl})^{*}$ & $\begin{array}{c}18529 \\
(18415-18 \text { 643) }\end{array}$ & $\begin{array}{c}16442 \\
(16293-16591)\end{array}$ & $\begin{array}{c}19973 \\
(19781-20165)\end{array}$ & $\begin{array}{c}23821 \\
(23512-24131)\end{array}$ & $\begin{array}{c}8476 \\
(7894-9057)\end{array}$ & $\begin{array}{c}13141 \\
(12220-14063)\end{array}$ \\
\hline \multicolumn{7}{|l|}{ Colorectal } \\
\hline No. of patients & 38108 & 8269 & 9124 & 10755 & 6848 & 3112 \\
\hline No. (\%) used radiation & $8979(23.6)$ & $1052(12.7)$ & $1979(21.7)$ & $3803(35.4)$ & $1877(27.4)$ & $268(8.6)$ \\
\hline Cost, \$, mean $(95 \% \mathrm{Cl})^{*}$ & $\begin{array}{c}15177 \\
(14899-15456)\end{array}$ & $\begin{array}{c}10613 \\
(9809-11416)\end{array}$ & $\begin{array}{c}17400 \\
(16807-17992)\end{array}$ & $\begin{array}{c}18853 \\
(18439-19266)\end{array}$ & $\begin{array}{c}8444 \\
(7957-8932)\end{array}$ & $\begin{array}{c}11689 \\
(10077-13301)\end{array}$ \\
\hline \multicolumn{7}{|l|}{ Lung } \\
\hline No. of patients & 34809 & 6104 & 2855 & 6989 & 17714 & 1147 \\
\hline No. (\%) used radiation & $23158(66.5)$ & $2330(38.2)$ & $1527(53.5)$ & 5864 (83.9) & $13005(73.4)$ & $432(37.7)$ \\
\hline Cost, \$, mean $(95 \% \mathrm{Cl})^{*}$ & $\begin{array}{c}10818 \\
(10669-10966)\end{array}$ & $\begin{array}{c}7982 \\
(7610-8353)\end{array}$ & $\begin{array}{c}13002 \\
(12321-13682)\end{array}$ & $\begin{array}{c}17790 \\
(17416-18165)\end{array}$ & $\begin{array}{c}8019 \\
(7877-8160)\end{array}$ & $\begin{array}{c}8009 \\
(7093-8925)\end{array}$ \\
\hline \multicolumn{7}{|l|}{ Prostate } \\
\hline No. of patients & 45258 & 10154 & 22103 & 5664 & 4058 & 3279 \\
\hline No. (\%) used radiation & 23207 (51.3) & $3228(31.8)$ & $13433(60.8)$ & $3701(65.3)$ & $2478(61.1)$ & $367(11.2)$ \\
\hline Cost, \$, mean $(95 \% \mathrm{Cl})^{*}$ & $\begin{array}{c}16887 \\
(16 \text { 648-17 125) }\end{array}$ & $\begin{array}{c}6467 \\
(6006-6928)\end{array}$ & $\begin{array}{c}20543 \\
(20 \text { 219-20 867) }\end{array}$ & $\begin{array}{c}17765 \\
(17168-18362)\end{array}$ & $\begin{array}{c}10264 \\
(9717-10812)\end{array}$ & $\begin{array}{c}10564 \\
(8985-12142)\end{array}$ \\
\hline
\end{tabular}

\section{Prostate cancer}

There were 45258 men diagnosed with prostate cancer. Just over half (23 653 (52.3\%]) were not admitted to hospital and thus did not have a Charlson Comorbidity Index score. Less than $4 \%(1535$ [3.4\%]) died during the 1-year follow-up period (Table 1). About half of the patients received cancerrelated medications (22 599 (49.9\%]) and radiation treatment (23 207 (51.3\%]). Radiation use was highest among those with stage II or III disease (Table 3).

The relatively low cost of prostate cancer treatments was reflected in the mean cancer-related medication cost $(\$ 1211$, $95 \%$ CI \$1175-\$1247), in contrast to that of radiation (\$16 887, 95\% CI \$16 648-\$17 125). The overall mean cost of medication increased as the stage of cancer increased, with the highest cost at stage IV (\$3236, 95\% CI 3060-3413). Costs of treatment drugs were highest for stage IV prostate cancer. Radiation costs were similar between stage II and III disease (Figure 1D, Figure 2D).

\section{Interpretation}

Using 2 novel costing algorithms leveraging population-level administrative databases, we found that, in general, stage III and IV cancers were the most expensive stages for both medications and radiation across all 4 disease sites in Ontario. Certain subtypes within each cancer type showed greater costs in the first year after diagnosis.
The costing algorithms used in the current study provide more detail by disease subtype than other methodologies. Previous published costing studies ${ }^{4-8}$ using the person-level case-costing methodology algorithm underestimated the critical costs related to cancer treatment around medications and radiation, as one cannot easily identify cancer-specific drugs and supportive drugs, or treatment and planning radiation costs. A recent systematic review of studies examining radiation costs showed that there is a wide range of costs, ${ }^{10}$ with some based on US estimates ${ }^{11-14}$ or older data. ${ }^{15}$

Our costing algorithms have face validity when compared with methods and studies conducted by other Canadian and international investigators. ${ }^{16-21} \mathrm{We}$ expect costs from other administrative databases studies not using our costing algorithms to have lower overall costs, and we expect differences in costs when compared to international studies. For example, our overall mean 1-year medication cost for prostate cancer (\$1211) was higher than that reported by Krahn and colleagues $^{16}$ (\$514 in 2007 Canadian dollars) because our work included additional medication databases (e.g., supportive medications), as well as using more current data (their results are based on analyses conducted more than a decade $\mathrm{ago}^{22}$ ). Radiation costs in the study by Krahn and colleagues ${ }^{16}$ were reported as negligible because the databases for planning, treatment and operational costs were not included. Moreover, Krahn and colleagues ${ }^{16}$ did not assess stage-based costing; rather, they focused on phase of treatment. 
A

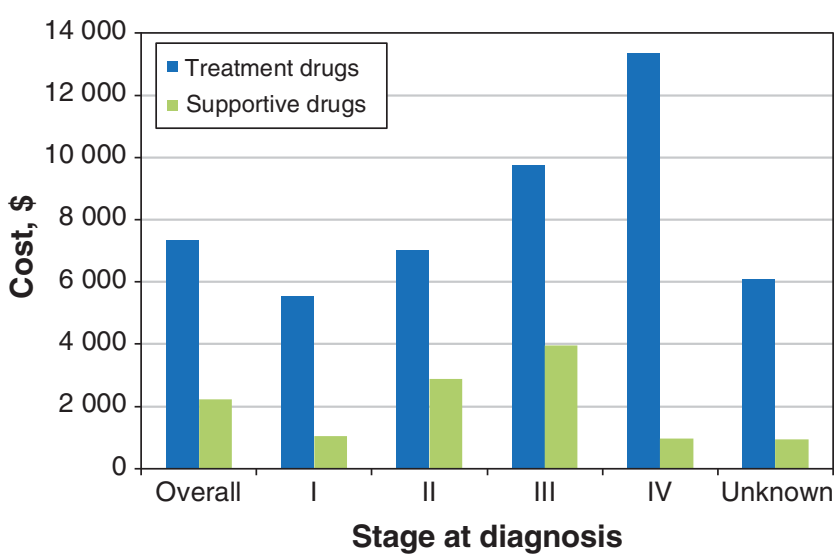

C

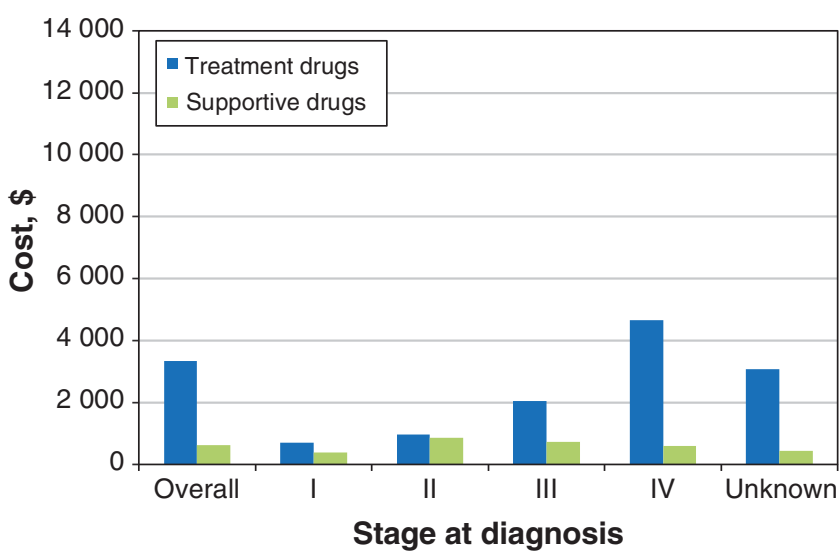

B

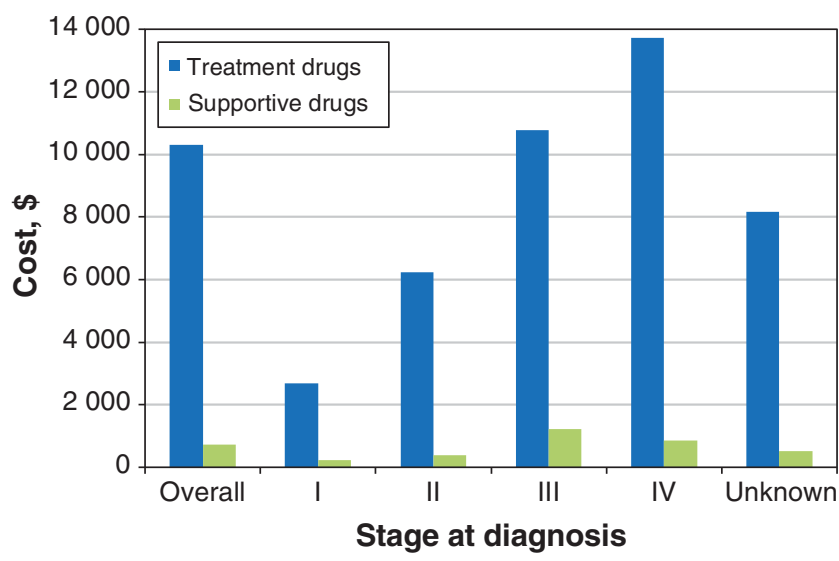

D

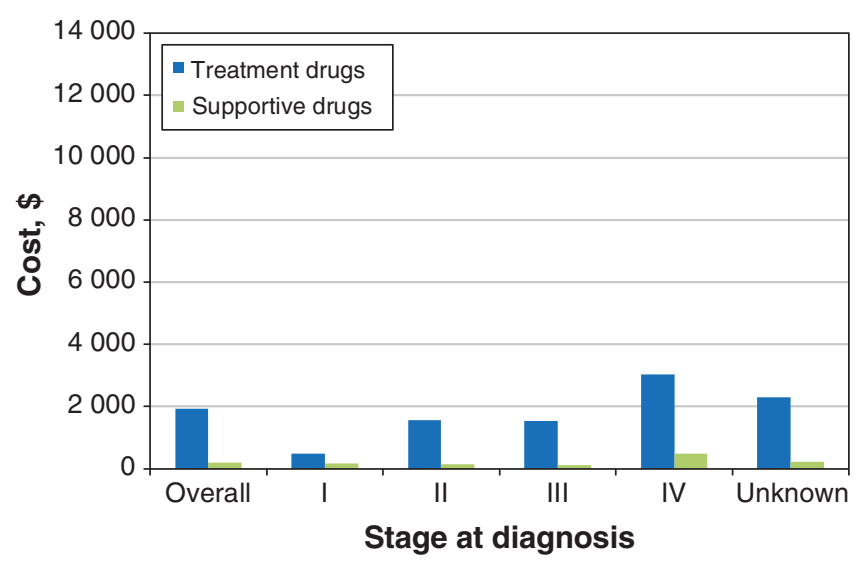

Figure 1: Disaggregated mean cancer-related medication costs (treatment and supportive) for breast (A), colorectal (B), lung (C) and prostate (D) cancer by cancer stage at diagnosis among those who had a nonzero cost.

Our 1-year mean radiation costs of $\$ 16442$ for women with stage I breast cancer and $\$ 19973$ for stage II disease are in line with those from insurance claims for radiation in women with stage I-II breast cancer in the United States, US\$14 910. ${ }^{17}$ Mean medication costs were lower in our study given our cohort of women with early-stage disease: stage I $\$ 5409$, stage II $\$ 8519$, compared to US\$13 373 in the US cohort. These variances likely reflect differences in resources included in the costing analyses, as well as different health system frameworks, but highlight opportunities for decreasing health care system costs.

The present work sets the stage for establishing the health care system costs for cancer-related medications and radiation therapy, which can be used as a baseline, and costs of future innovations and incremental analyses. Although all cohorts were anchored at 2015, the costing algorithms created can examine the cost by any disease site, stage or phase of care, including updated time horizons, based on the defined cohorts because it uses a resource-based bottom-up calcula- tion. The algorithms can be used for any period investigated and be based on data availability and time horizon. In this study, we used a 365-day time horizon because the last members of the cohort included in the analysis had only 1 year of follow-up data in the data sets available.

Other investigators have leveraged the 2 cancer-specific costing algorithms. ${ }^{23,24}$ Ongoing analyses include examining costs in melanoma, pancreatic, gastric, esophageal and lung cancer. Although not described here, each individual resource used by a cohort of patients can be identified and explored with this micro-economic costing algorithm approach. Future work will examine other phases of care in the care continuum and will generate costs across other disease sites and subtypes.

\section{Limitations}

Strengths of this work include the comprehensiveness of the data for the entire Ontario population of 14 million, but there are also limitations. Our analysis provides costs for medication and radiation based on the algorithm variables but does not 
A

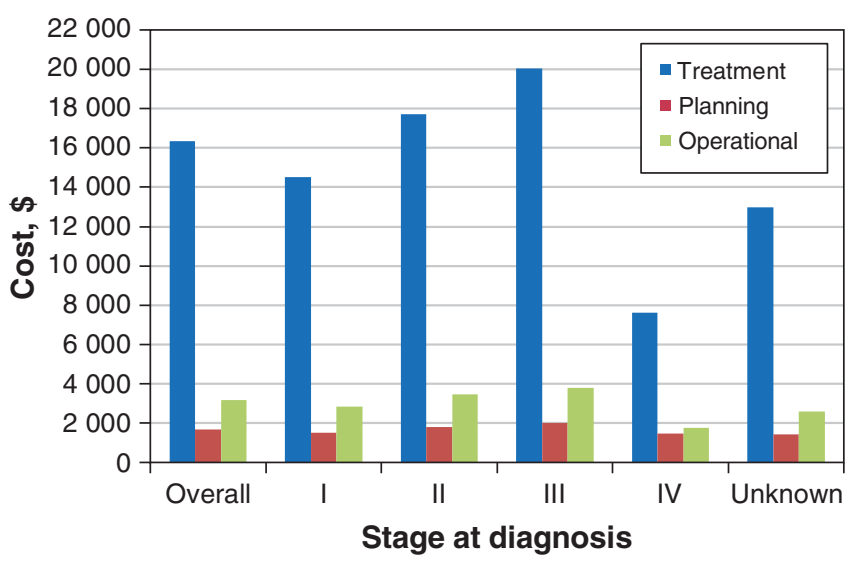

C

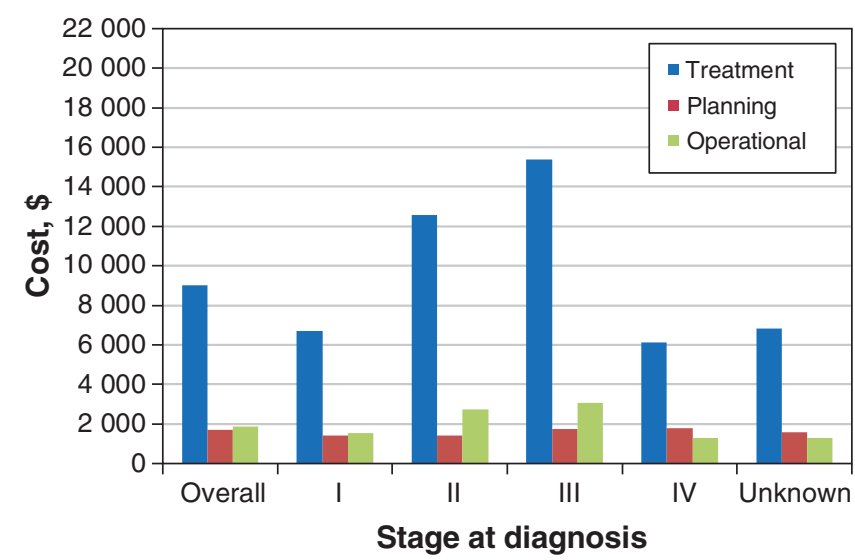

B

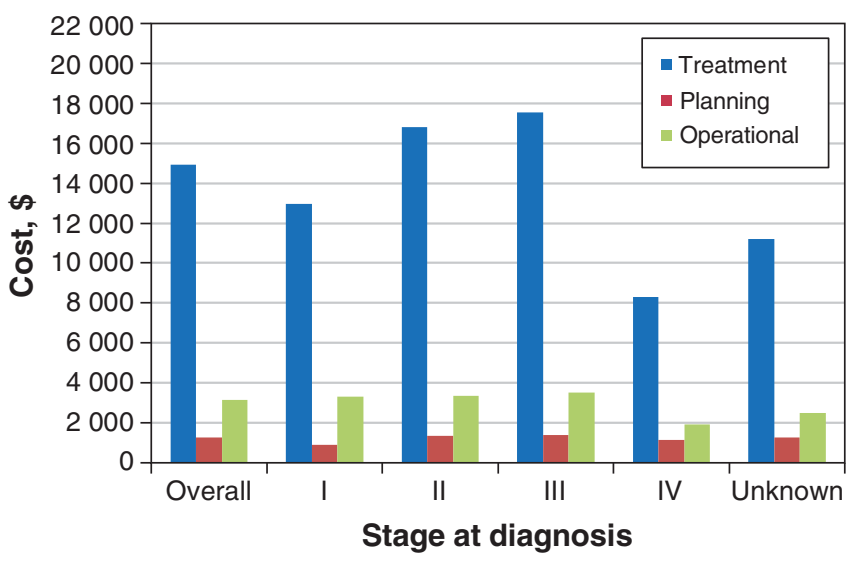

D

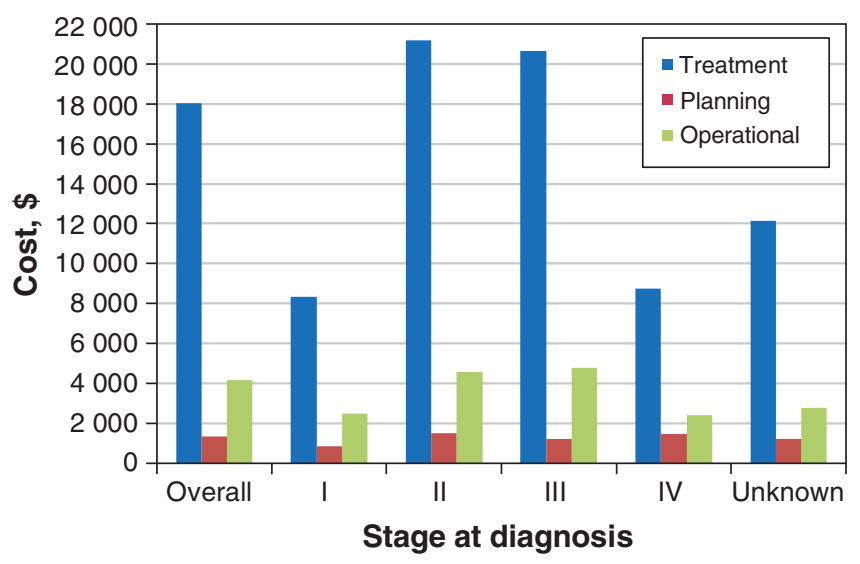

Figure 2: Disaggregated mean radiation treatment costs (planning, treatment and operational) for breast $(A)$, colorectal $(B)$, lung $(C)$ and prostate (D) cancer by cancer stage at diagnosis among those who had a nonzero cost.

provide costs for other health care system encounters. Moreover, this analysis provides costs only for initial care in the first year after a cancer diagnosis and does not consider the cost of the life cycle (e.g., maintenance and survivorship). We used this time horizon as it was in line with other phase-based costing approaches. ${ }^{22,25,26} \mathrm{We}$ did, however, establish that, even in 1 year, there were survival differences across the 4 most common cancers, with 1-year survival for patients with breast cancer being highest. Depending on the disease progression during the 1-year time horizon, end-of-life costs may be calculated.

In addition, it is important to highlight that we report only on costs to the publicly funded health care system. We did not have access to costs incurred by the individual patient (e.g., those aged less than $65 \mathrm{yr}$ ) or private insurers, and, as such, they are not addressed in this analysis. Understanding this type of use and cost information would be important in cohorts in which the mean age at diagnosis is less than 65 years, as the costs of drugs for oral use in those patients are unknown.

\section{Conclusion}

Understanding the resources and costs associated with publicly funded medications and radiation therapy is important in health care system planning and sustainability in a singlepayer system. Our work updates previous costing estimates, as we have included comprehensive data on cancer-related medication and radiation treatment. More refined costing estimates are useful as inputs to allow for more robust health economic modelling and health care system planning.

\section{References}

1. Schnipper LE, Meropol N. ASCO addresses the rising cost of cancer care. 7 Oncol Pract 2009:5:214-5.

2. Statistics Canada. Postal Code ${ }^{\mathrm{OM}}$ Conversion File (PCCF), reference guide. Available: https://www150.statcan.gc.ca/n1/pub/92-154-g/92-154-g2017001 -eng.htm (accessed 2019 July 23).

3. Wodchis WP, Bushmeneva K, Nikitovic M, et al. Guidelines on person-level costing using administrative databases in Ontario. Working paper series volume 1. Toronto: Health System Performance Research Network; 2013.

4. Guilcher SJ, Bronskill SE, Guan J, et al. Who are the high-cost users? A method for person-centred attribution of health care spending. PLoS One 2016;11:e0149179. 
5. Laberge M, Wodchis WP, Barnsley $\mathrm{J}$, et al. Costs of health care across primary care models in Ontario. BMC Health Serv Res 2017;17:511.

6. Rosella LC, Fitzpatrick T, Wodchis WP, et al. High-cost health care users in Ontario, Canada: demographic, socio-economic, and health status characteristics. BMC Health Serv Res 2014;14:532.

7. Wodchis WP, Austin PC, Henry DA. A 3-year study of high-cost users of health care. CMA7 2016;188:182-8.

8. Lunsky Y, de Oliveira C, Wilton A, et al. High health care costs among adults with intellectual and developmental disabilities: a population-based study. $\mathcal{F}$ Intellect Disabil Res 2019;63:124-37.

9. Mittmann N, Cheng SY, Liu N, et al. The generation of two specific cancer costing algorithms using Ontario administrative databases. Curr Oncol 2019;26: e682-92.

10. Rahman F, Seung SJ, Cheng SY, et al. Radiation costing methods: a systematic review. Curr Oncol 2016;23:e392-408.

11. Furlan JC, Chan KK, Sandoval GA, et al. The combined use of surgery and radiotherapy to treat patients with epidural cord compression due to metastatic disease: a cost-utility analysis. Neuro Oncol 2012;14:631-40.

12. Hodges JC, Beg MS, Das P, et al. Cost-effectiveness analysis of intensity modulated radiation therapy versus 3-dimensional conformal radiation therapy for anal cancer. Int 7 Radiat Oncol Biol Phys 2014;89:773-83.

13. Kim H, Rajagopalan MS, Beriwal S, et al. Cost-effectiveness analysis of single fraction of stereotactic body radiation therapy compared with single fraction of external beam radiation therapy for palliation of vertebral bone metastases. Int 7 Radiat Oncol Biol Phys 2015;91:556-63.

14. Konski A. Cost-effectiveness of intensity-modulated radiation therapy. Expert Rev Pharmacoecon Outcomes Res 2005;5:137-40.

15. Earle C, Coyle D, Smith A, et al. The cost of radiotherapy at an Ontario regional cancer centre: a re-evaluation. Crit Rev Oncol Hematol 1999;32:87-93.

16. Krahn MD, Bremner KE, Luo J, et al. Health care costs for prostate cancer patients receiving androgen deprivation therapy: treatment and adverse events. Curr Oncol 2014;21:e457-65.

17. Blumen H, Fitch K, Polkus V. Comparison of treatment costs for breast cancer, by tumor stage and type of service. Am Health Drug Benefits 2016;9:23-32.

18. Sun L, Legood R, Dos-Santos-Silva I, et al. Global treatment costs of breast cancer by stage: a systematic review. PLoS One 2018;13:e207993.

19. Laudicella M, Walsh B, Burns E, et al. Cost of care for cancer patients in England: evidence from population-based patient-level data. Br 7 Cancer 2016;114: 1286-92.

20. Greenup RA, Blitzblau RC, Houck KL, et al. Cost implications of an evidencebased approach to radiation treatment after lumpectomy for early-stage breast cancer. F Oncol Pract 2017;13:e283-90.

21. McGuffin M, Merino T, Keller B, et al. Who should bear the cost of convenience? A cost-effectiveness analysis comparing external beam and brachytherapy radiotherapy techniques for early stage breast cancer. Clin Oncol (R Coll Radiol) 2017;29:e57-63.

22. Krahn MD, Zagorski B, Laporte A, et al. Healthcare costs associated with prostate cancer: estimates from a population-based study. BfU Int 2010;105: 338-46.

23. Look Hong NJ, Cheng SY, Wright FC, et al. Resource utilization and disaggregated cost analysis for initial treatment of melanoma. 7 Cancer Pol 2018;16:63-9.

24. Mittmann N, Earle CC, Cheng SY, et al. Population-based study to determine the health system costs of using the 21-gene assay. 7 Clin Oncol 2018;36:238-43.
25. de Oliveira C, Pataky R, Bremner KE, et al. Phase-specific and lifetime costs of cancer care in Ontario, Canada. BMC Cancer 2016;16:809.

26. de Oliveira C, Bremner KE, Pataky R, et al. Understanding the costs of cancer care before and after diagnosis for the 21 most common cancers in Ontario: a population-based descriptive study. CMA7 Open 2013;1:E1-8.

Affiliations: Sunnybrook Research Institute (Mittmann, Seung) and Odette Cancer Centre (Look Hong, Earle, Cheung, Coburn, DeAngelis), Sunnybrook Health Sciences Centre; Cancer Care Ontario (Mittmann), Toronto, Ont.; Canadian Agency for Drugs and Technologies in Health (Mittmann), Ottawa, Ont.; ICES (Liu, Cheng, Saxena, Earle, Cheung, Coburn); Health Outcomes and PharmacoEconomic (HOPE) Research Centre (Seung); University Health Network (Leighl), Toronto, Ont.; McMaster University (Evans), Hamilton, Ont.

Contributors: Nicole Mittmann and Soo Jin Seung conceived the study. Nicole Mittmann, Ning Liu, Stephanie Cheng, Soo Jin Seung and Farah Saxena contributed to the study design. Stephanie Cheng, Farah Saxena and Ning Liu analyzed the data. All of the authors contributed to data interpretation, drafting the manuscript and revising it critically for important intellectual content, approved the final version to be published and agreed to be accountable for all aspects of the work.

Funding: This study was supported by ICES, which is funded by an annual grant from the Ontario Ministry of Health and Long-Term Care, and by a Health Services Network grant from the Ontario Institute for Cancer Research.

Acknowledgement: The authors thank IMS Brogen for use of their Drug Information database.

Disclaimer: This study was supported by ICES, which is funded by an annual grant from the Ontario Ministry of Health and Long-Term Care (MOHLTC). The opinions, results and conclusions reported in this article are those of the authors and are independent from the funding sources. No endorsement by ICES or the Ontario MOHLTC is intended or should be inferred. Parts of this material are based on data or information compiled and provided by the Canadian Institute for Health Information (CIHI). However, the analyses, conclusions, opinions and statements expressed in the material are those of the authors and not necessarily those of CIHI. Parts of this material are based on data and information provided by Cancer Care Ontario (CCO). The opinions, results, views and conclusions reported in this paper are those of the authors and do not necessarily reflect those of CCO. No endorsement by CCO is intended or should be inferred.

Supplemental information: For reviewer comments and the original submission of this manuscript, please see www.cmajopen.ca/content/8/1/ E191/suppl/DC1. 